\title{
ERRATUM
}

A. T. Ford · T. P. Rodgers-Gray $\cdot$ I. M. Davies

A. M. Dunn · P. A. Read · C. D. Robinson · J. E. Smith

T. F. Fernandes

\section{Abnormal gonadal morphology in intersex, Echinogammarus marinus (Amphipoda): a possible cause of reduced fecundity?}

Published online: 13 July 2005

(C) Springer-Verlag 2005

\section{Marine Biology (2005) DOI s00227-005-1601-1}

The statement "A.T. Ford and T.P. Rodgers-Gray contributed equally to this work" is missing in the online version.

The online version of the original article can be found at http:// dx.doi.org/10.1007/s00227-005-1601-1

A. T. Ford $(\bowtie) \cdot$ P. A. Read · T. F. Fernandes

School of Life Sciences, Napier University, 10 Colinton Road, Edinburgh, EH10 5DT, UK

E-mail: a.ford@napier.ac.uk

Tel.: + 44-131-4552350

Fax: +44-131-4552291

T. P. Rodgers-Gray · A. M. Dunn · J. E. Smith

School of Biology, University of Leeds, Leeds, LS2 9JT, UK

I. M. Davies · C. D. Robinson

Fisheries Research Services Marine Laboratory, 375 Victoria

Road, PO Box 101, Aberdeen, AB11 9DB, UK 